\title{
Selective Vulnerability of Specific Retinal Ganglion Cell Types and Synapses after Transient Ocular Hypertension
}

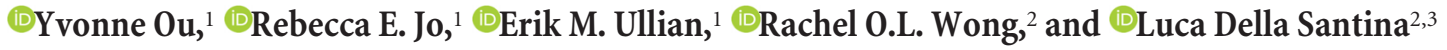 \\ ${ }^{1}$ Department of Ophthalmology, University of California, San Francisco, San Francisco, California 94143, ${ }^{2}$ Department of Biological Structure, University of \\ Washington, Seattle, Washington 98195, and ${ }^{3}$ Department of Pharmacy, University of Pisa, Pisa, Italy 56126
}

Key issues concerning ganglion cell type-specific loss and synaptic changes in animal models of experimental glaucoma remain highly debated. Importantly, changes in the structure and function of various RGC types that occur early, within $14 \mathrm{~d}$ after acute, transient intraocular pressure elevation, have not been previously assessed. Using biolistic transfection of individual RGCs and multielectrode array recordings to measure light responses in mice, we examined the effects of laser-induced ocular hypertension on the structure and function of a subset of RGCs. Among the $\alpha$-like RGCs studied, $\alpha$ OFF-transient RGCs exhibited higher rates of cell death, with corresponding reductions in dendritic area, dendritic complexity, and synapse density. Functionally, OFF-transient RGCs displayed decreases in spontaneous activity and receptive field size. In contrast, neither $\alpha 0 F F$-sustained nor $\alpha 0 \mathrm{~N}$-sustained RGCs displayed decreases in light responses, although they did exhibit a decrease in excitatory postsynaptic sites, suggesting that synapse loss may be one of the earliest signs of degeneration. Interestingly, presynaptic ribbon density decreased to a greater degree in the OFF sublamina of the inner plexiform layer, corroborating the hypothesis that RGCs with dendrites stratifying in the OFF sublamina may be damaged early. Indeed, OFF arbors of ON-OFF RGCs lose complexity more rapidly than $\mathrm{ON}$ arbors. Our results reveal type-specific differences in RGC responses to injury with a selective vulnerability of $\alpha$ OFF-transient RGCs, and furthermore, an increased susceptibility of synapses in the OFF sublamina. The selective vulnerability of specific RGC types offers new avenues for the design of more sensitive functional tests and targeted neuroprotection.

Key words: dendrite; glaucoma; light response; retinal ganglion cell; RGC type; synapse

Significance Statement

Conflicting reports regarding the selective vulnerability of specific retinal ganglion cell (RGC) types in glaucoma exist. We examine, for the first time, the effects of transient intraocular pressure elevation on the structure and function of various RGC types. Among the $\alpha$-like RGCs studied, $\alpha$ OFF-transient RGCs are the most vulnerable to transient transient intraocular pressure elevation as measured by rates of cell death, morphologic alterations in dendrites and synapses, and physiological dysfunction. Specifically, we found that presynaptic ribbon density decreased to a greater degree in the OFF sublamina of the inner plexiform layer. Our results suggest selective vulnerability both of specific types of RGCs and of specific inner plexiform layer sublaminae, opening new avenues for identifying novel diagnostic and treatment targets in glaucoma.

\section{Introduction}

In many neurodegenerative diseases of the CNS, subpopulations of cells within a specific region of the brain are more vulnerable to

\section{Received March 21, 2016; revised July 19, 2016; accepted July 20, 2016}

Author contributions: Y.O., E.M.U., R.O.L.W., and L.D.S. designed research; Y.O., R.E.J., and L.D.S. performed research; Y.O., R.E.J., and L.D.S. analyzed data; Y.O., E.M.U., R.O.L.W., and L.D.S. wrote the paper.

This work was supported by National Institutes of Health Grant KEY022676A to Y.0., Research to Prevent Blindness Career Development Award to Y.O., American Glaucoma Society Young Clinician-Scientist Award to Y.0., Ron and Anita Wornick and That Man May See to Y.O. and E.M.U., National Institutes of Health Grant R01MH099595 to E.M.U., Research to Prevent Blindness Walt and Lilly Disney Award for Amblyopia Research to E.M.U., National Institutes of Health Grant EY EY017101 to R.O.L.W., and National Institutes of Health NEI EY002162 Core Grant for Vision Research and Research to Prevent Blindness Unrestricted Grant at the University of California, San Francisco. We thank Karen Chu for assistance in some image acquisition; and Felice Dunn and Dang Dao for helpful discussions of the manuscript. injury and may have distinct patterns of degeneration. Thus, a detailed understanding of neuronal types that are selectively vulnerable may provide insights into the mechanisms of neurodegeneration and novel treatment targets (Seeley, 2008). Glaucoma is a neurodegenerative disease of the retina and the leading cause of irreversible blindness worldwide (Quigley and Broman, 2006). The hallmark feature of glaucomatous neurodegeneration is the

\footnotetext{
The authors declare no competing financial interests.
}

Correspondence should be addressed to either of the following: Dr. Yvonne Ou, University of California, San Francisco, 10 Koret Way, Room K203, Box 0730, San Francisco, CA 94143, E-mail: yvonne.ou@ucsf.edu; or Dr. Luca Della Santina, Department of Pharmacy, Via Bonanno, 6, 56126 Pisa, Italy. E-mail: luca.dellasantina@gmail.com. DOI:10.1523/JNEUROSCI.0940-16.2016

Copyright $\odot 2016$ the authors $\quad 0270-6474 / 16 / 369240-13 \$ 15.00 / 0$ 
A

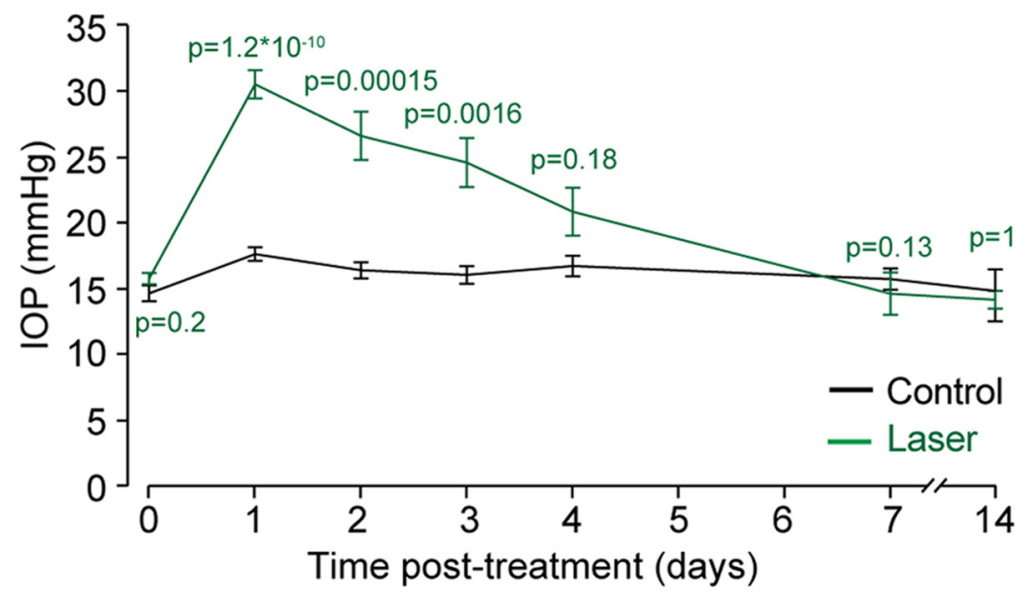

B

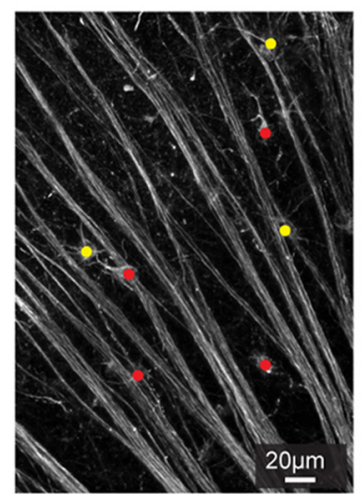

Control

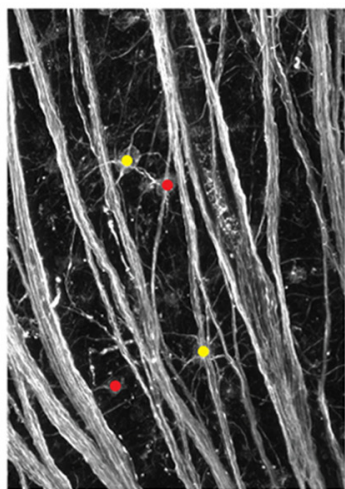

Laser 7 days

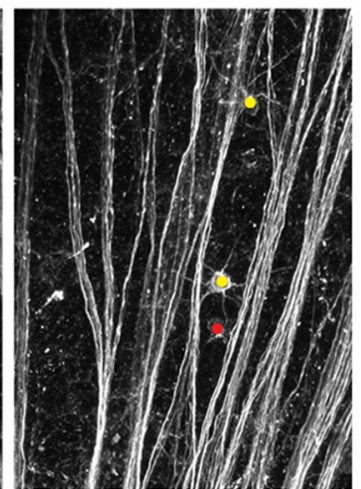

Laser 14 days
C

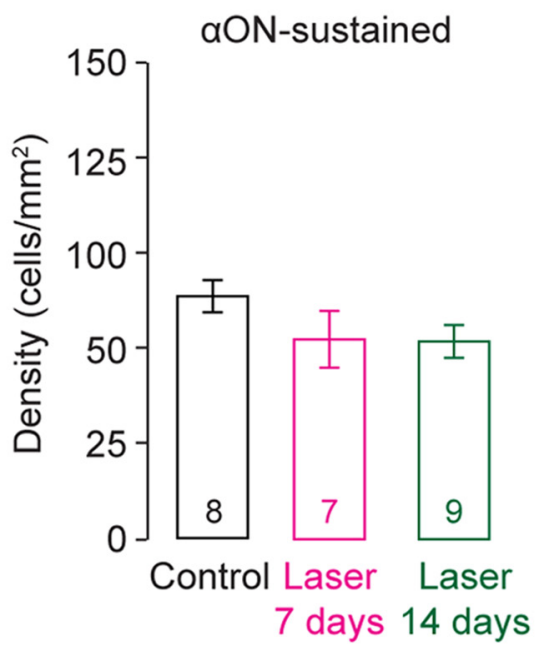

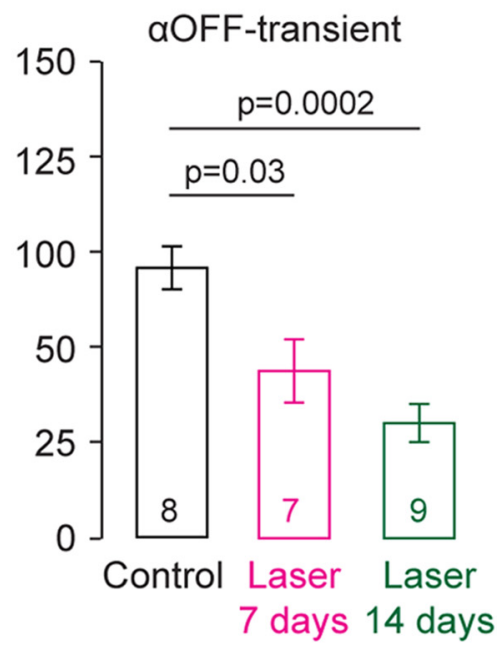

Figure 1. Transient ocular hypertension results in preferential loss of OFF-transient versus ON-sustained $\alpha$ RGCs. $\boldsymbol{A}$, The laserinduced ocular hypertension model results in transient IOP elevation with peak IOP $1 \mathrm{~d}$ after laser treatment and a return to baseline by $4 \mathrm{~d}$ after treatment. Shown here are the IOP measurements in control (black) and lasered eyes (green). $N$ ranged from 17 to 39 animals for each time point (see Materials and Methods). Only animals used in these experiments are included. Error bars indicate \pm SEM. Statistics: Wilcoxon-Mann-Whitney rank sum test. $\boldsymbol{B}$, Maximum intensity projections of image stacks illustrating SMl-32-labeled $\alpha \mathrm{RGC}$ somata, axons, and primary dendrites. $\alpha 0 \mathrm{~N}$-sustained (yellow dots) and $\alpha 0 \mathrm{FF}$-transient (red dots) RGCs are identified by their bright cell bodies and dendritic stratification. C, Average densities of $\alpha 0 \mathrm{FF}$-transient RGCs and $\alpha 0 \mathrm{~N}$-sustained RGCs. Numbers inside histograms indicate number of animals with 3-6 images quantified for each animal. Statistics: WilcoxonMann-Whitney rank sum test.

death of the retinal ganglion cells (RGCs), which are the output neurons of the retina making synapses onto visual targets in the brain. Elevated intraocular pressure (IOP) is a major risk factor of the disease, but even patients whose IOP is controlled will continue to slowly lose RGCs and vision (Heijl et al., 2002; Ederer et al., 2004). Indeed, little is known about how the neurodegenerative process progresses once IOP returns to baseline values, which is of critical importance for discovering treatments that are independent of IOP lowering.

Previous work in humans and various experimental glaucoma models has come to different conclusions as to whether IOP differentially affects specific types of RGCs (Quigley et al., 1987, 1988; Glovinsky et al., 1991; Weber et al., 1998; Morgan et al., 2000; Pavlidis et al., 2003; Shou et al., 2003; Jakobs et al., 2005; Li et al., 2006; Della Santina et al., 2013; Feng et al., 2013; El-Danaf and Huberman, 2015). A major challenge is in identifying common patterns of the disease manifesting across different RGC types, which are estimated to be as many as $30+$ types in the mouse retina (Sanes and Masland, 2015; Baden et al., 2016). Before molecular tools were available, landmark studies demonstrated strong structurefunction correlation in ON and OFF RGCs, such that dendrites of ON and OFF RGCs arborize in the inner and outer laminae of the inner plexiform layer (IPL) and respond to increases and decreases in light intensity, respectively (Cleland et al., 1975; Famiglietti and Kolb, 1976; Famiglietti et al., 1977). Recent studies suggest that RGCs with dendrites stratifying in the OFF sublamina are among the earliest to undergo morphologi$\mathrm{cal}$ and functional alterations in chronic experimental glaucoma (Della Santina et al., 2013; El-Danaf and Huberman, 2015). However, a detailed time course of both morphological and functional changes after transient IOP elevation, especially of presynaptic and postsynaptic alterations in the IPL, has not been well characterized.

In clinical practice, IOP is lowered using medications, laser, or surgery, and yet glaucoma patients often continue to exhibit visual function decline and optic nerve degeneration. In an acute angle closure crisis, the IOP elevation can be relatively shortlived, but optic nerve degeneration can continue even once IOP is normalized (Aung et al., 2004; Andreatta et al., 2014, 2015). Therefore, a model of transient IOP elevation is useful for investigating these realworld scenarios. Our purpose was to determine the effects of acute and shortterm IOP elevation on the structure and function of various RGC types at different 
early time points during which RGCs undergo degeneration. We modified a laserinduced ocular hypertension model in which aqueous outflow is transiently obstructed (Salinas-Navarro et al., 2009; Fu and Sretavan, 2010). We examined individual $\alpha$-like RGCs ( $\alpha$ RGCs) and their presynaptic and postsynaptic components to compare the progression of morphologic changes, including dendritic and synaptic parameters at early time points when RGC degeneration was still ongoing. We also performed multielectrode array recordings to measure RGC responses to light, and distinguished among 4 major functional types (ON sustained or transient; OFF sustained, or transient). Together, our findings suggest that, among $\alpha$ RGCs, $\alpha$ OFF-transient RGCs exhibit greater rates of cell death with corresponding alterations in structure and function. Furthermore, synapse loss, occurring to a greater degree in the OFF sublamina of the IPL, appears to be one of the earliest anatomical changes in response to elevated IOP.

\section{Materials and Methods}

Animals. Female CD-1 albino mice were purchased from Charles River Laboratories and were housed in animal facilities at the University of California, San Francisco. All experiments were conducted in animals 3-4 months of age. All animal procedures were approved by the Institutional Animal Care and Use Committees at University of California, San Francisco and the University of Washington, Seattle.

Laser-induced ocular hypertension. Mice were anesthetized with intraperitoneal injections of ketamine/xylazine and IOP measured for each eye using the Tonolab rebound tonometer (Colonial Medical Supply). The probe was triggered with a custom foot pedal to minimize movement of the instrument during IOP measurement. For the laser procedure, mice were placed under a surgical microscope and an endoprobe attached to a diode laser $(532 \mathrm{~nm}$; Lumenis) was used to photocoagulate the limbal and at least 3-6 episcleral vessels in the left eye ( $300 \mathrm{~mW}$ laser power, $0.5 \mathrm{~s}$ duration, $100 \mu \mathrm{m}$ diameter spot size). The translimbal laser treatment was performed over 330 degrees sparing the nasal aspect and the long posterior ciliary arteries. This procedure leads to the transient obstruction of aqueous outflow. After surgery, lubricant ophthalmic ointment was applied to the operative eye. Each animal received only one laser photocoagulation treatment with the untreated contralateral eye serving as the control. IOP was monitored for 7-14 $\mathrm{d}$ and mice that demonstrated at least 30\% increase in IOP followed by a decline to baseline were included in the study, whereas mice that developed an IOP > $50 \mathrm{mmHg}$ were excluded. Mice with overt signs of corneal edema, hyphema, and inflammation were killed and excluded from the study. Because it was not always possible to measure the IOP for all mice (due to both transit time and quarantine restrictions upon housing of some animals transferred between institutions), the total number of mice from which we obtained IOP measurements varied between time points (Baseline: $N=34-39$ mice; 1 d: $N=32-37$ mice; 2 d: $N=27-34$ mice; $3 \mathrm{~d}: N=23-30$ mice; $4 \mathrm{~d}: 24-31$ mice; $7 \mathrm{~d}: 17-21$ mice). All lasered eyes exhibited IOP elevation, although some $(\sim 15 \%)$ did not demonstrate at least a $30 \%$ IOP increase and were not included in the study. However, it was not possible to design a control in which the eye was lased but the IOP was not increased, and thus the contralateral untreated eye served as a control.

Biolistic transfection. Mice were anesthetized by avertin injection (150 $\mathrm{mg} / \mathrm{kg}$ ) or isoflurane overdose and killed by cervical dislocation. Eyes
Laser 7 days
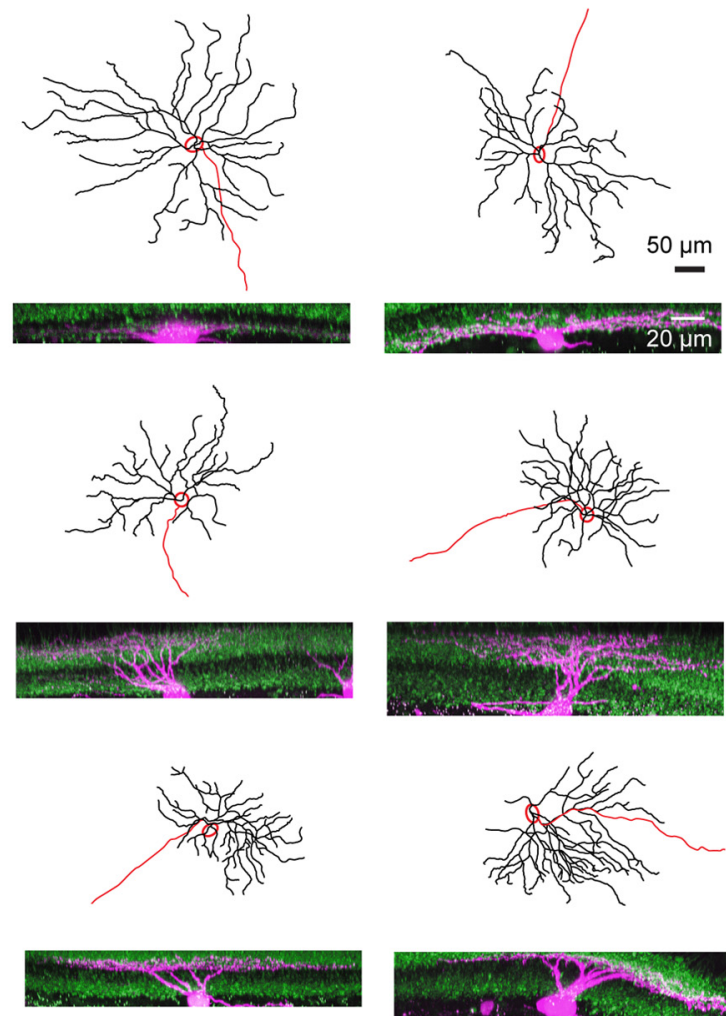

Laser 14 days
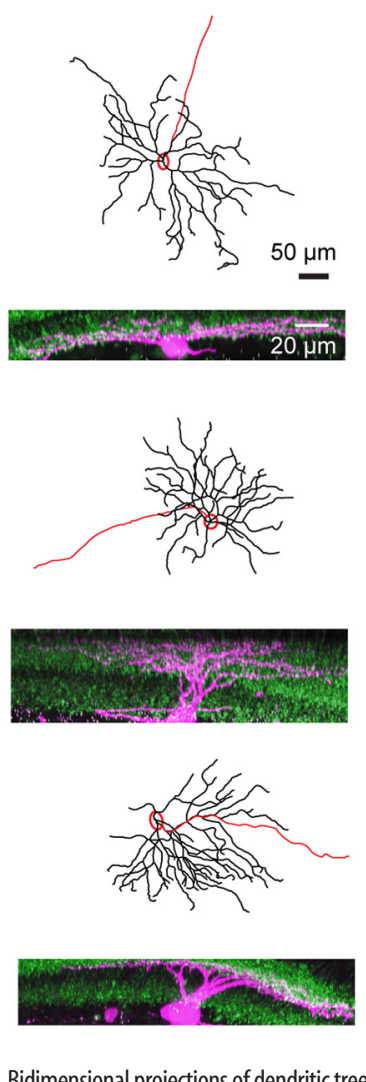

eyes. Bidimensional projections of dendritic tree skeletons (black) obtained from confocal image stacks of $\alpha \mathrm{RGCs}$ in control and laser-induced ocular hypertensive eyes 7 and $14 \mathrm{~d}$ after treatment. Red represents cell body and axon of the same cells. Orthogonal rotations of the dendritic arbors are shown below the $x$-y views as maximum intensity projection of the confocal image stack. Magenta represents cell labeling. Green labeling represents axonal arbors of Type 2 (upper band) and Type 6 (lower band) bipolar cells by synaptotagmin 2, used here to delineate IPL stratification levels.

were removed and placed in oxygenated mouse ACSF, containing the following (in mM): $130 \mathrm{NaCl}, 2.5 \mathrm{KCl}, 1 \mathrm{MgCl}_{2}{ }^{*} 6 \mathrm{H}_{2} \mathrm{O}, 2 \mathrm{CaCl}_{2}{ }^{*} 2 \mathrm{H}_{2} \mathrm{O}$, $1.25 \mathrm{NaHPO}_{4}, 20$ glucose, $21 \mathrm{NaHCO}_{3}$. Retinas were isolated from the eyecup under a dissection microscope and mounted onto nitrocellulose filter paper (Millipore). DNA-coated gold particles were prepared by coating $12.5 \mathrm{mg}$ of $1.6 \mu \mathrm{m}$ gold particles (Bio-Rad) with $20 \mu \mathrm{g}$ of $C M V$ : tdTomato and $7 \mu \mathrm{g}$ of $C M V$ :PSD95-YFP plasmids. A Helios gene gun (Bio-Rad) was used to biolistically deliver plasmid-coated gold particles to whole-mounted retinas. A suspension of DNA-coated gold particles in ethanol was precipitated onto the inner surface of Teflon tubing (BioRad) and subsequently cut into short segments (12 mm long). Gold particles were propelled onto the tissue using helium gas at 40 psi. Retinas were then transferred to an oxygenated and humidified chamber and maintained for $29 \mathrm{~h}$ at $32^{\circ} \mathrm{C}$, allowing fluorescent protein to be expressed sufficiently for subsequent imaging.

Immunohistochemistry. To visualize $\alpha$ RGCs (see Fig. 1), whole-mount retinas were harvested as described above and then fixed in 4\% PFA in ACSF, pH 7.4, for $30 \mathrm{~min}$. After fixation, retinas were rinsed twice in $1 \times$ PBS and processed for immunostaining as follows: blocked in blocking buffer containing 5\% normal donkey serum and 0.5\% Triton X-100 in PBS overnight at $4^{\circ} \mathrm{C}$ followed by 4 night incubation using primary antibodies, including anti-nonphosphoneurofilament $\mathrm{H}$ (mouse 1:1000, SMI-32, Covance, RRID: AB_2314904) and anti-ChAT (goat 1:100, AB144P, Millipore, RRID: AB_2079751). Retinas were then washed $3 \times$ 20 min in PBS and incubated overnight at $4^{\circ} \mathrm{C}$ with the corresponding secondary antibodies. Cell nuclei were stained by applying TO-PRO3 iodide for $30 \mathrm{~min}$ (1:2000; Invitrogen). Retinas were then washed with PBS three times and mounted onto glass slides using Fluoromount-G (Southern Biotechnology). For the biolistic transfection experiments (see Figs. 2345-6), retinas were fixed in 4\% PFA in ACSF for 15-30 min as 
A
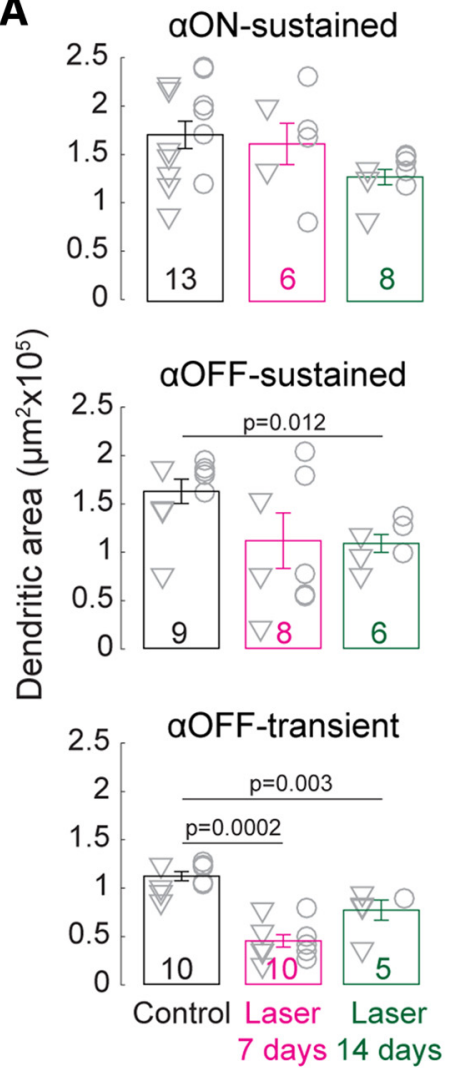

B
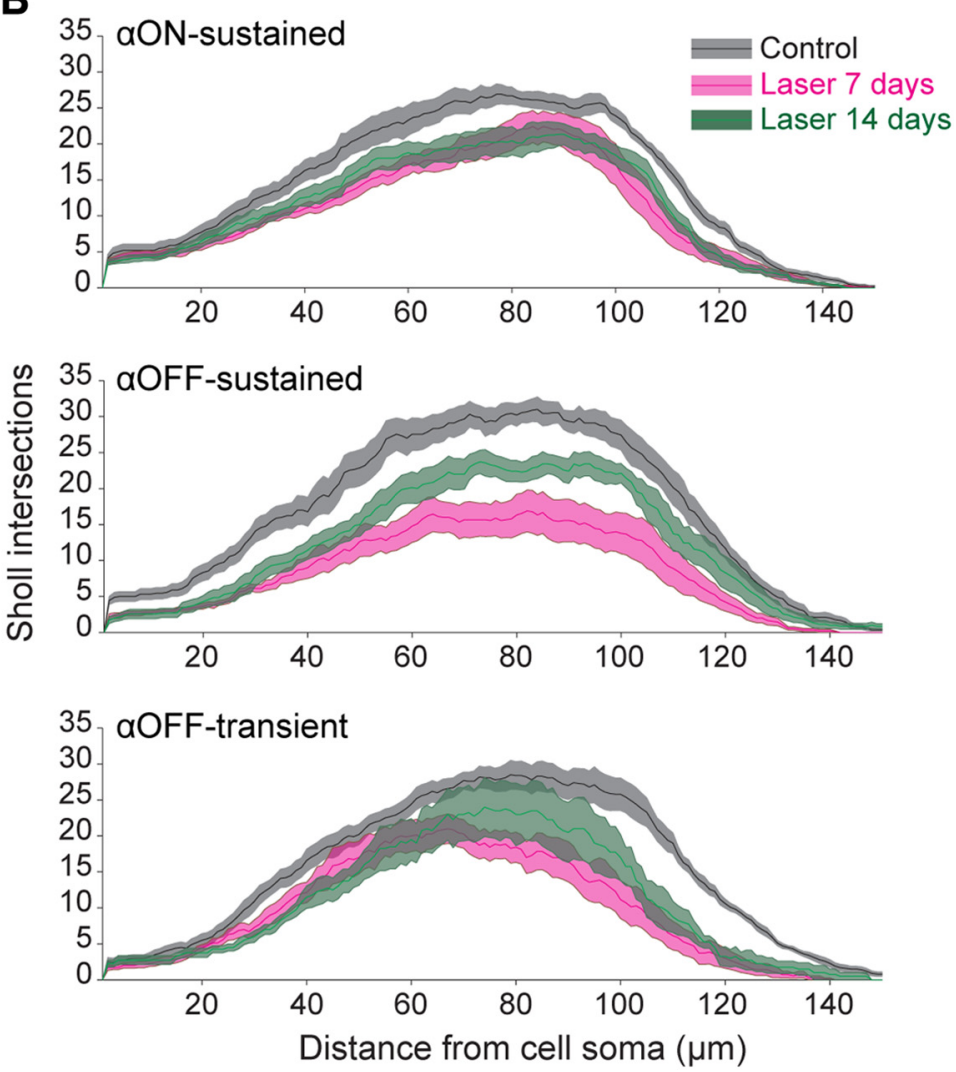

Figure 3. Dendritic area and complexity are reduced in OFF $\alpha \mathrm{RGCS}$. A, Both $\alpha$ OFF-sustained and $\alpha$ OFF-transient RGCs exhibit decreased dendritic territory, with the latter exhibiting this decrease earliest at $7 \mathrm{~d}$ after IOP elevation. Gray represents individual cell values. Circles represent nasal retina. Triangles represent temporal retina. $\boldsymbol{B}$, All three $\alpha$ RGC types examined show a decrease in dendritic complexity. Solid line indicates average value of sampled cells. Colored band indicates SEM. Cell numbers are noted in the histograms; $4-6$ animals per group. Statistics: Wilcoxon-MannWhitney rank sum test.

described above. Following an overnight block, the retinas were incubated with the following primary antibodies for 5 nights: mouse monoclonal anti-CtBP2 antibody (1:1000; BD Biosciences, RRID: AB_399431) and anti-synaptotagmin 2 (mouse 1:200, Syt2, ZIRC, RRID: $\left.A B \_10013783\right)$. After washing and incubating with the appropriate secondary antibodies (Alexa, Invitrogen, 1:1000; or Dylight, Jackson ImmunoResearch Laboratories, 1:1000, conjugated fluorophores) overnight at $4^{\circ} \mathrm{C}$, retinas were washed again and mounted onto glass slides using Vectashield (Vector Laboratories).

Image acquisition. All images were acquired with a laser scanning confocal microscope (Zeiss LSM 700 or Olympus FV 1000). For SMI-32 labeled RGCs, image stacks were acquired using a 1.3 NA $40 \times$ oil objective (voxel size: $0.156 \times 0.156 \times 1 \mu \mathrm{m}$ ). To image individually labeled RGCs or presynaptic ribbons, image stacks were acquired with either a 1.3 NA $40 \times$ oil objective or a 1.35 NA $60 \times$ oil objective (voxel size: $0.098 \times 0.098 \times 0.3 \mu \mathrm{m})$.

Quantification of SMI-32 labeled $\alpha$ RGCs. $\alpha \mathrm{ON}$-sustained ( $\alpha \mathrm{ON}-\mathrm{S}$ ) and $\alpha$ OFF-transient ( $\alpha$ OFF-T) RGCs were identified based on the intense SMI-32 labeling of their large somata and dendritic arbors. The $\alpha$ RGCs can be distinguished based upon their dendritic stratification relative to labeled cholinergic ChAT plexuses and cell bodies (Bleckert et al., 2014). Two individuals manually counted $\alpha \mathrm{ON}-\mathrm{S}$ and $\alpha$ OFF-T RGCs at three different locations: inner, middle, and outer third of the retina from the optic nerve head in both the dorsonasal and ventral-nasal leaflets. Cell density was expressed as the average number of cells per square millimeter.

Dendritic parameters and synapse density quantification. To measure dendritic arbor parameters, dendrites of individual $\alpha$ RGCs and ON-OFF RGCs were skeletonized using Imaris (Bitplane, RRID: SCR_007370) and dendritic parameters were measured from a two-dimensional projection of the skeleton using custom-written MATLAB (The Math-
Works, RRID: SCR_001622) routines (Della Santina et al., 2013). Briefly, dendritic area was defined as the area of the convex hull enclosing the dendritic arbor. Dendritic complexity was calculated using the Sholl analysis function within Imaris.

To determine PSD95-YFP puncta distribution on dendrites of individual $\alpha$ RGCs and ON-OFF RGCs, image stacks were acquired at $0.098 \times 0.098 \times 0.3 \mu \mathrm{m}$. Dendritic stratification patterns were visualized relative to the position of synaptotagmin-2. We used a semiautomated method for quantifying synapse density as previously described (Morgan et al., 2008) with modifications (Della Santina et al., 2013). Briefly, ImageJ (RRID: SCR_003070) was used to median filter the images to remove the thermal noise of the microscope's photomultipliers. Using the $3 \mathrm{D}$ dendritic skeleton generated above (Imaris), custom-written MATLAB routines then created a binary mask to include PSD95-YFP signal only within the dendrites. Details of candidate puncta identification and final validation are previously described (Della Santina et al., 2013). The average linear density of puncta is the total number of puncta divided by the total length of the dendritic tree. Linear density of puncta as a function of distance from the cell soma is calculated by quantifying puncta density along the dendritic skeleton within a moving window of $10 \mu \mathrm{m}$. Control RGCs were pooled from 7 and $14 \mathrm{~d}$ given that there were no differences between groups.

Multielectrode array recording. Details of the microelectrode array recording, visual stimulation, spike sorting, and data analysis have been previously reported (Della Santina et al., 2013). Briefly, mice were darkadapted $2-3 \mathrm{~h}$ before the experiment, and subsequently, the following procedures were performed in a completely darkened room under IR illumination using microscope-mounted infrared converters (B.E. Meyers). Eyes were enucleated and corneas were punctured with a 30 gauge needle to allow diffusion of oxygenated $\left(95 \% \mathrm{O}_{2} / 5 \% \mathrm{CO}_{2}\right)$ 
ACSF. The retina dissection was performed as described previously (Della Santina et al., 2013).

Once dissected, the retina was oriented ganglion cell side down in contact with a 60 electrode MEA (Multi-Channel Systems), arranged in an $8 \times 8$ square grid (electrode diameter: $10 \mu \mathrm{m}$, spacing either 200 or $100 \mu \mathrm{m}$ ). The tissue was perfused continuously with oxygenated ACSF, and the temperature of the perfusate was maintained at $31^{\circ} \mathrm{C}-33^{\circ} \mathrm{C}$. Signals were bandpass filtered $(100-3000 \mathrm{~Hz})$ and digitized at $20 \mathrm{kHz}$ rate. Thresholds were set 5 times above SD of the baseline noise levels for each recording channel and, if necessary, adjusted manually.

Visual stimulation. Visual stimuli were presented on a monochrome organic lightemitting diode display (eMagin; mean luminance at the retina $\sim 10^{5}$ photoisomerizations per middle-wavelength-sensitive cone per second; resolution, $800 \times 600$ pixels; $75 \mathrm{~Hz}$ vertical refresh rate). The stimuli, focused on the photoreceptors of the retina, illuminated the back focal plane of a $10 \times$ objective (UPlanFL N; Olympus) mounted on an inverted microscope (Axiovert S100; Zeiss) in place of the condenser. Visual stimuli were programmed using MATLAB and the Cogent graphics toolbox extensions (Wellcome Laboratory of Neurobiology, University College London). The presented set of stimuli consisted of full-field square wave and checkerboard Gaussian white-noise patterns. Full-field square wave stimuli were delivered as $100 \%$ contrast steps of 15 repetitions of $4 \mathrm{~s}$ ON, $5 \mathrm{~s}$ OFF. For checkerboard stimuli, every $40 \mathrm{~ms}$ (effective refresh rate $25 \mathrm{~Hz}$ ), the intensity of squares (51 $\mu \mathrm{m}$ side length) on the retina was randomly chosen from a Gaussian distribution with constant mean and SD.

Spike sorting and data analysis. After recording, for each electrode, spikes were sorted into single-cell trains using Offline Sorter (Plexon, RRID: SCR_000012) (Tian and Copenhagen, 2001; Demas et al., 2003; Kerschensteiner et al.,

2008). Spike sorting quality was evaluated by verifying refractory periods of the sorted trains, such that only cells with $<0.2 \%$ interspike intervals smaller than $2 \mathrm{~ms}$ were analyzed. Using custom software written in MAT$\mathrm{LAB}$, cells were clustered into functional types using their light response to light step stimuli (Della Santina et al., 2013). Spontaneous spike rate, light responses of RGCs, and generator signal were all quantified as previously described (Della Santina et al., 2013). Control RGCs were pooled from 7 and $14 \mathrm{~d}$ given that there were no differences between groups.

Presynaptic ribbon density quantification. To determine CtBP2 puncta distribution within an IPL volume, image stacks were acquired at $0.098 \times$ $0.098 \times 0.3 \mu \mathrm{m}$, sampling an IPL volume with a superficial area of $50 \times$ $50 \mu \mathrm{m}$. For each data point, three independent IPL volumes were measured and averaged from the ventral retina. We used the semiautomated method for quantifying synapse density as previously described (Morgan et al., 2008) with modifications (Della Santina et al., 2013) and extended the search of candidate puncta to the whole acquired IPL volume. Briefly, ImageJ was used to median filter the images to remove the thermal noise of the microscope's photomultipliers. Details of candidate puncta identification and manual final validation were performed as previously described (Della Santina et al., 2013). The average density of puncta is the total number of puncta identified in the volume divided by the volume size. The local CtBP2 density was calculated as a function of IPL depth, with $0 \%$ representing the location of the RGC layer and $100 \%$ being the inner limit of the inner nuclear layer, as indicated by the first CtBP2positive cell nuclei labeled in each respective layer.

Statistical analysis. All data are shown as mean \pm SEM. Statistical analysis was performed using the two-sided Wilcoxon rank sum test unless otherwise specified.

\section{Results}

The laser-induced ocular hypertension model transiently elevates IOP and results in loss of $\alpha$ RGCs in a type-specific manner

With modification to a laser-induced ocular hypertension technique (Salinas-Navarro et al., 2009; Fu and Sretavan, 2010), IOP increases to peak levels $(30.3 \pm 1.07 \mathrm{mmHg}$ laser vs $17.4 \pm 0.52$ $\mathrm{mmHg}$ control) $24 \mathrm{~h}$ after laser photocoagulation (Fig. $1 \mathrm{~A}$ ), and then gradually returns to baseline levels by $4 \mathrm{~d}$ after IOP elevation $(20.7 \pm 1.82 \mathrm{mmHg}$ laser vs $16.5 \pm 0.78 \mathrm{mmHg}$ control, $N=$ 17-39 animals across time points). The average IOPs of laser versus control mice were not statistically significantly different at $14 \mathrm{~d}(13.7 \pm 0.67 \mathrm{mmHg}$ laser vs $14.1 \pm 1.97 \mathrm{mmHg}$ control, $N=$ 3 animals). Although we cannot rule out the possibility of retinal ischemia, previous work demonstrates that peak IOPs at this level in CD-1 mice are unlikely to lower the ocular perfusion pressure 

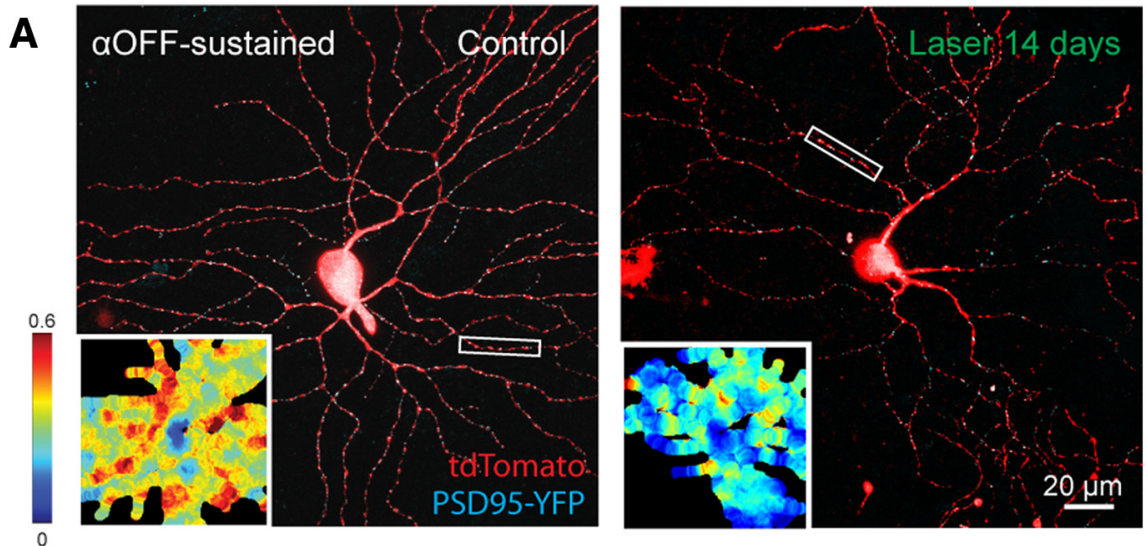

B
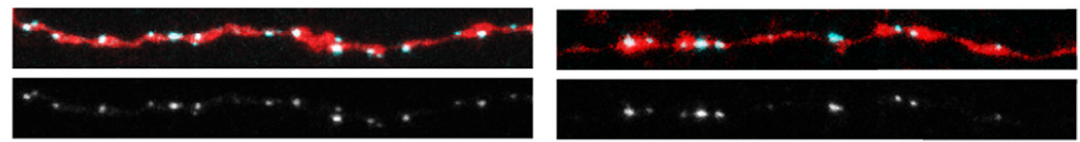

\section{C}
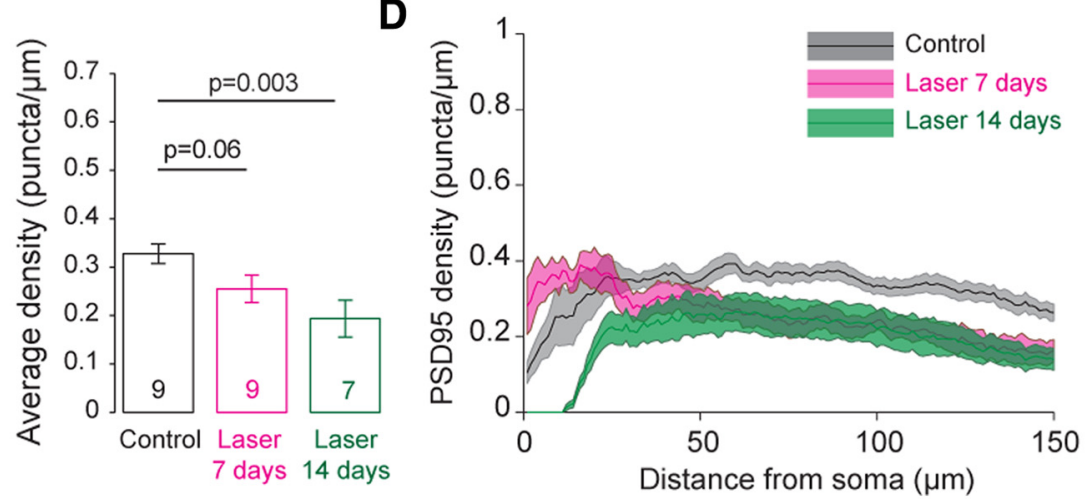

Figure 5. $\alpha$ OFF-sustained RGCS show decreased synaptic density $14 \mathrm{~d}$ after IOP elevation. $\boldsymbol{A}$, Example of biolistically labeled $\alpha$ OFF-sustained RGC in laser-induced ocular hypertensive (14 d) and control eyes showing coexpression of PSD95-YFP and tdT0mato (RGC soma and dendrites). Inset, Heat maps of the linear density of PSD95-YFP puncta. Hotter colors represent higher PSD95 puncta density. $\boldsymbol{B}$, Magnified views of the dendrites and puncta in the boxed regions in A. C, Average linear density of PSD95-YFP puncta. Cell numbers are noted in the histograms; 6 animals per group. Statistics: Wilcoxon-Mann-Whitney rank sum test. $\boldsymbol{D}$, Average linear density of PSD95-YFP puncta as a function of distance from the soma. At $7 \mathrm{~d}$, there is greater loss of puncta distally compared with closer to the soma. Solid line indicates average value of sampled cells. Colored band indicates SEM. types are similar (Bleckert et al., 2014). At 7 and $14 \mathrm{~d}$ after IOP elevation (Fig. $1 B, C$ ), there is a statistically significant loss of $\alpha$ OFF-T RGCs compared with control, whereas the densities of $\alpha \mathrm{ON}-\mathrm{S}$ RGCs at each time point are not significantly different from that of controls. Given this differential rate of cell loss, we next explored and compared morphological changes of $\alpha \mathrm{ON}$ - and $\alpha \mathrm{OFF}-\mathrm{RGCs}$ in response to IOP elevation.

\section{Dendritic arbor morphology is differentially altered among $\alpha$ RGCs} and on varying time scales

To assess anatomical changes in $\alpha$ RGCs early after IOP elevation, we used a biolistic gene gun labeling technique to label individual RGCs 7 and $14 \mathrm{~d}$ after IOP elevation (see Materials and Methods). This labeling technique results in sparse but complete cellular labeling of the RGCs, which permits detailed visualization of dendritic arbors (for examples, see Fig. 2). $\alpha$ OFF-T were the only RGC type to demonstrate a significant reduction in dendritic area $7 \mathrm{~d}$ after IOP elevation $(p=$ 0.0002, $N=4-6$ animals per group), whereas $\alpha$ OFF-S RGCs also showed a reduction in dendritic area that became statistically significant $14 \mathrm{~d}$ after IOP elevation $(p=0.24$ and $p=0.01$ after 7 and $14 \mathrm{~d}$, respectively, $N=4-6$ animals per group) (Fig. $3 A$ ). In contrast, $\alpha \mathrm{ON}-\mathrm{S}$ RGCs did not exhibit a decrease in dendritic area at 7 or $14 \mathrm{~d}$ after IOP elevation $(p=0.76$ and $p=0.07$ after 7 and $14 \mathrm{~d}$ respectively, $N=4-6$ animals per group). While all three types revealed a decrease in complexity in lasered versus control eyes at $7 \mathrm{~d}$ as indicated by Sholl analysis (Fig. 3B) $(p=0.03, p=0.0002, p=0.0002$ for enough to induce global retinal ischemia (Desai et al., 1997; Fu and Sretavan, 2010).

To assess whether there were any differential rates of RGC death among RGCs of varying types, we examined three types of $\alpha$ RGCs: $\alpha$ OFF-transient ( $\alpha$ OFF-T), $\alpha$ OFF-sustained ( $\alpha$ OFF-S), and $\alpha \mathrm{ON}$-sustained ( $\alpha \mathrm{ON}-\mathrm{S}$ ). (Pang et al., 2003; Schubert et al., 2005; Völgyi et al., 2005; van Wyk et al., 2009). $\alpha$ RGCs are characterized by having large somas and dendritic arbors. They differ in their physiological properties and dendritic stratification depth, with the $\alpha \mathrm{ON}-\mathrm{S}, \alpha \mathrm{OFF}-\mathrm{T}$, and $\alpha \mathrm{OFF}-\mathrm{S}$ RGCs having dendrites stratifying at $30 \%, 50 \%$, and $70 \%$ of the IPL depth, respectively (Sanes and Masland, 2015). We used the antibody SMI-32, which is directed against nonphosphorylated neurofilament heavy chain, to identify $\alpha \mathrm{ON}-\mathrm{S}$ and $\alpha$ OFF-T RGCs based on bright staining of the cell bodies, distinguishing between the two types based on the laminar arborization of their dendrites (Coombs et al., 2006; Huberman et al., 2008; Bleckert et al., 2014). $\alpha$ OFF-S RGCs are not brightly labeled by SMI-32. Because the density of $\alpha \mathrm{ON}-\mathrm{S}$ varies considerably across the retina, we examined the density of $\alpha \mathrm{ON}-\mathrm{S}$ and $\alpha \mathrm{OFF}-\mathrm{T}$ RGCs in the dorsonasal and ventral-nasal leaflets where cell densities of both $\alpha \mathrm{ON}-\mathrm{S}, \alpha \mathrm{OFF}-\mathrm{S}$, and $\alpha \mathrm{OFF}-\mathrm{T}$, respectively, $n=4-6$ animals per group), there are some interesting features to note that differed among the types. First, when examining dendritic complexity at the distal dendrites, $\alpha$ OFF-T RGCs demonstrated the greatest reduction. While the $\alpha$ OFF-S and $\alpha$ OFF-T RGCs appear to exhibit some recovery in dendritic complexity $14 \mathrm{~d}$ after IOP elevation compared with $7 \mathrm{~d}$, this was not statistically significant for any of the $\alpha$ RGC types $(p=0.80, p=0.11$, and $p=0.41$, for $\alpha$ ON-S, $\alpha$ OFF-S, and $\alpha$ OFF-T, respectively, $N=4-6$ animals per group). Similarly, no significant recovery was observed for dendritic area between 7 and $14 \mathrm{~d}(p=0.14, p=0.57, p=0.19$ for $\alpha \mathrm{ON}-\mathrm{S}, \alpha \mathrm{OFF}-\mathrm{S}$, and $\alpha \mathrm{OFF}-\mathrm{T}$, respectively, $N=4-6$ animals per group).

\section{$\alpha$ RGCs undergo early synaptic disassembly}

Earlier work suggests that postsynaptic alterations occur before dendritic shrinkage in a microbead occlusion model of chronic IOP elevation (Della Santina et al., 2013). We wondered whether synaptic connectivity was disrupted earlier in our model of laserinduced ocular hypertension; therefore, we investigated the distribution of excitatory postsynaptic sites along the dendritic 
arbor of $\alpha$ RGCs at 7 and $14 \mathrm{~d}$ after IOP elevation. To label excitatory postsynaptic sites, we cotransfected CMV:PSD95-YFP and $C M V$ :tdTomato plasmids to retinas from lasered and control eyes and then masked the dendritic YFP signal to isolate PSD95 puncta within the dendrites of individual RGCs (see Materials and Methods). All three types of $\alpha$ RGCs showed a decrease in PSD95 density (Figs. 4-6) and loss of excitatory postsynaptic sites at $14 \mathrm{~d}$ after IOP elevation. However, at $7 \mathrm{~d}$, the decrease for $\alpha$ OFF-S RGCs was not statistically significant, whereas $\alpha \mathrm{OFF}-\mathrm{T}$ and $\alpha$ ON-S RGCs already exhibited significant decreases in PSD95 density $(N=6$ animals per group). We also obtained the average PSD95 density (normalized to control cells of the same type) for each type to determine whether there was a preferential loss of excitatory postsynaptic sites in ON $(\alpha \mathrm{ON}-\mathrm{S})$ versus OFF ( $\alpha$ OFF-S and $\alpha$ OFF-T) RGCs. At 7 and $14 \mathrm{~d}$ after IOP elevation, the normalized average PSD95 density between ON versus OFF $\alpha$ RGCs was not statistically significant $(p=0.23$ and $p=0.62$, at 7 and $14 \mathrm{~d}$, respectively, $N=6$ animals per group). Given these early synaptic changes and differential dendritic alterations observed among $\alpha$ RGCs, we then determined whether there are corresponding effects on RGC functionality.

\section{OFF-transient RGCs exhibit the earliest functional decline}

To assess the functional activity of many RGCs after a transient period of IOP elevation, multielectrode array recordings were performed. RGCs were classified functionally into four groups based on their response to a square-wave light stimulus: ON and OFF RGCs responded by increasing or decreasing their average spike rate to light onset, respectively. ON and OFF RGCs were further functionally subgrouped based on whether their responses were transient or sustained. Based on these criteria, we sorted the RGCs into four functional groups: ON sustained (ON-S), ON transient (ON-T), OFF sustained (OFF-S), OFF transient (OFFT). $\alpha$ RGCs examined morphologically in this study are also but not exclusively included within these wider functional groups, in which they are likely represented by the largest receptive field (RF) cells within each functional group. We first examined spontaneous activity for each RGC functional type based on average spike responses in the dark (Fig. $7 A, B$ ). Spontaneous activity was decreased only in the OFF-T RGCs $14 \mathrm{~d}$ after IOP elevation $(p=$ 0.84 at $7 \mathrm{~d}, p=0.014$ at $14 \mathrm{~d}, N=6$ animals per group). None of the other three functional types showed statistically significant decreases in spontaneous activity $(p=0.17, p=0.41, p=0.24$ for ON-S, ON-T, and OFF-S, respectively at $14 \mathrm{~d}, N=6$ animals per group).

We next investigated whether there was any change in RF size among the four RGC functional types (Fig. $7 A, C$ ). This was performed by using Gaussian white noise stimulation and reverse- correlation methods to simultaneously evaluate the spatial structure of the RF of neighboring cells. As with spontaneous activity, the OFF-T RGCs were the only type to show a decrease in RF size, as early as $7 \mathrm{~d}$ after IOP elevation. The other RGC types showed no change in RF size at either 7 or $14 \mathrm{~d}$ after IOP elevation $(p=0.21, p=0.26, p=0.61$ at $7 \mathrm{~d}, p=0.39, p=0.36, p=0.72$ at $14 \mathrm{~d}$ for ON-S, ON-T, OFF-S, respectively, $N=6$ animals per group). We also assessed the maximum spike rate 7 and $14 \mathrm{~d}$ after IOP elevation for each RGC type (Fig. $7 D, E$ ). OFF-T RGCs were the only type to show a decrease in maximum spike rate as early as $7 \mathrm{~d}$ after IOP elevation. Interestingly, OFF-S RGCs demonstrated an increase in maximum spike rate compared with control.

\section{Presynaptic disassembly occurs early and to a greater degree} in the OFF sublamina of the IPL

Given the RGC type-specific structural and functional alterations, we wondered whether presynaptic inputs might also be affected. Because ON and OFF $\alpha$ RGCs appear to lose their excitatory synapses with slightly different rates and spatial structure with regards to distance from the cell soma, we investigated whether the presynaptic inputs at excitatory synapses in the IPL undergo a similar fate, possibly identifying a 
A

Spontaneous activity

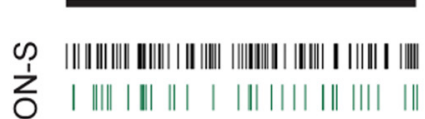

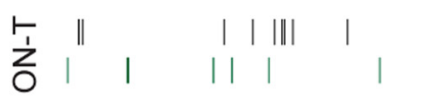

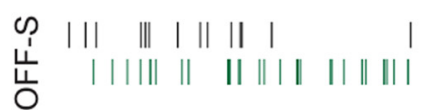

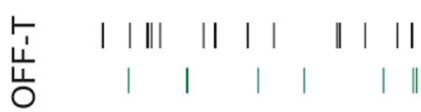

B

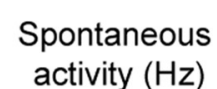

C activity $(\mathrm{Hz})$
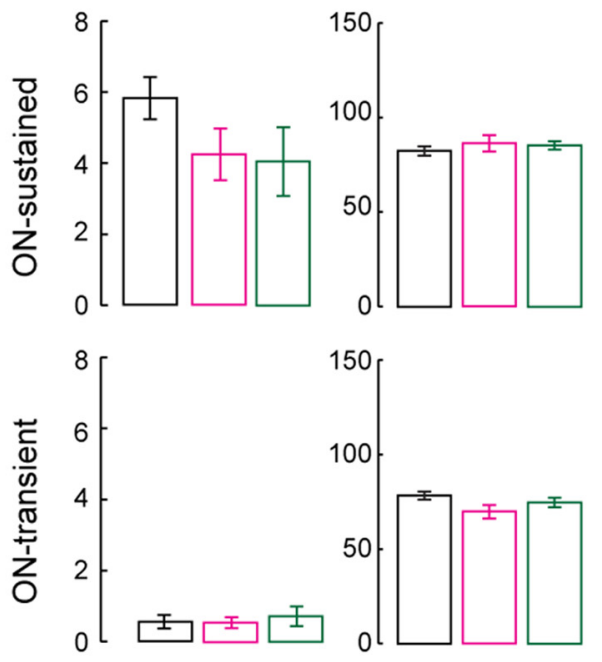

40
30
20
10
0

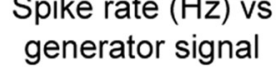

III

|| |
Square-wave light stimulation

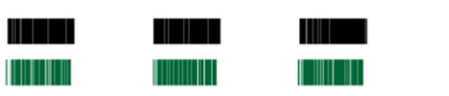

\|\|\|\|$|\|||| \mid$

||

Spatial RF center

Control Laser $14 d$
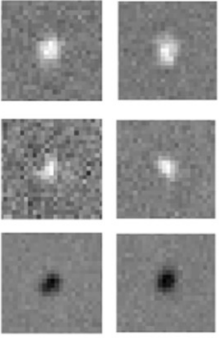

IIII

|| | $\underline{2 \mathrm{~s}}$

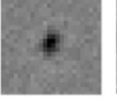

\section{$\mathbf{E}$}

Max. spike rate $(\mathrm{Hz})$
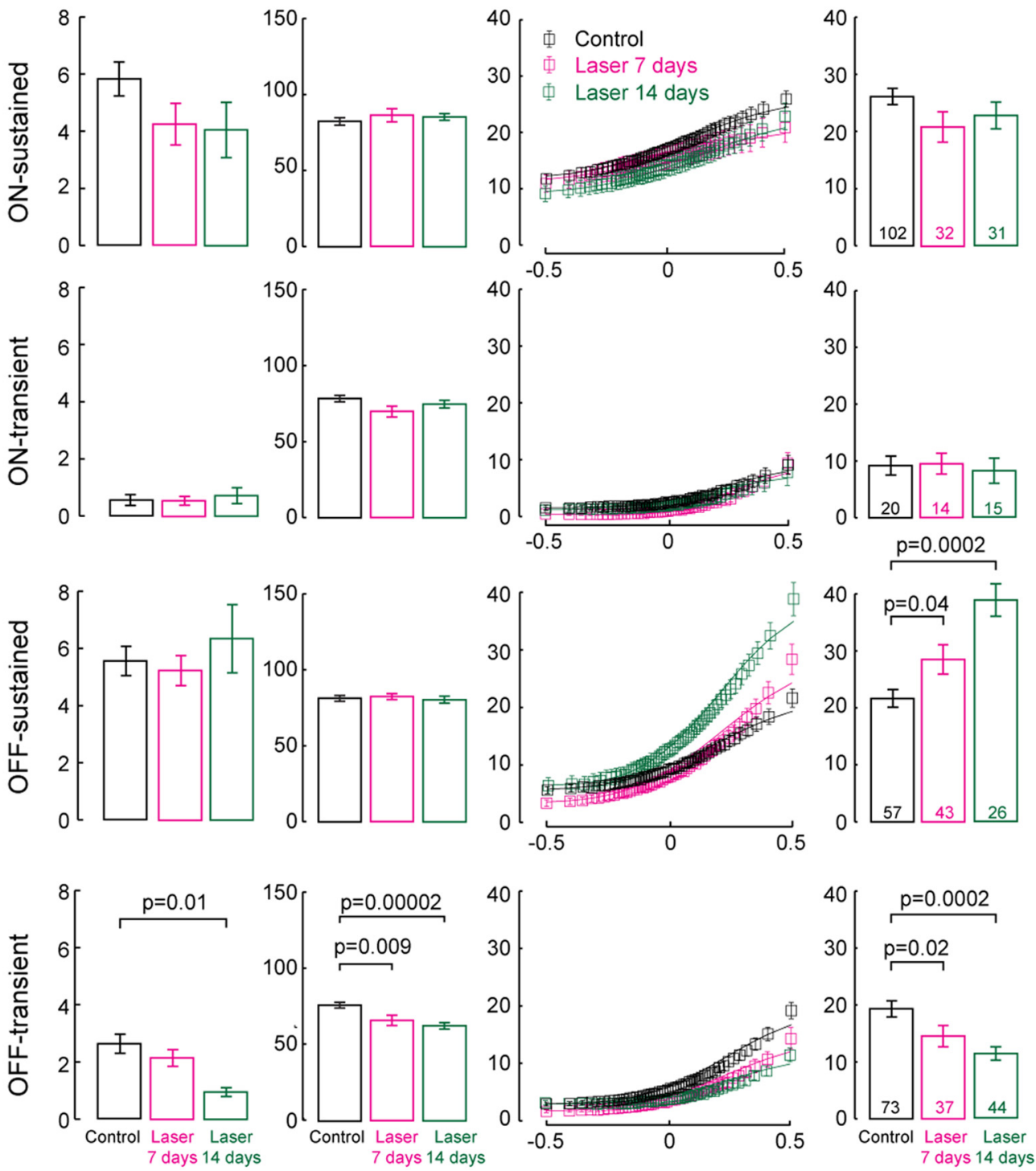

Figure 7. Spontaneous activity, RF center size, and maximum spike rate are reduced in OFF-transient RGCs after transient ocular hypertension. A, Spike raster plots of example RGCs of each functional type showing spontaneous activity and their responses to square-wave full-field light stimulation. Shown here are RGCs recorded from control (black lines) or laser-induced ocular hypertensive eyes (green lines) $14 \mathrm{~d}$ after treatment. Right images represent spatial RFs for the same cells obtained from reverse correlation analysis of the response to Gaussian white noise light stimulation. B, Quantification of the average spontaneous spike rates of each RGC type examined reveals that only OFF-transient RGCs exhibit a decrease in (Figure legend continues.) 
A
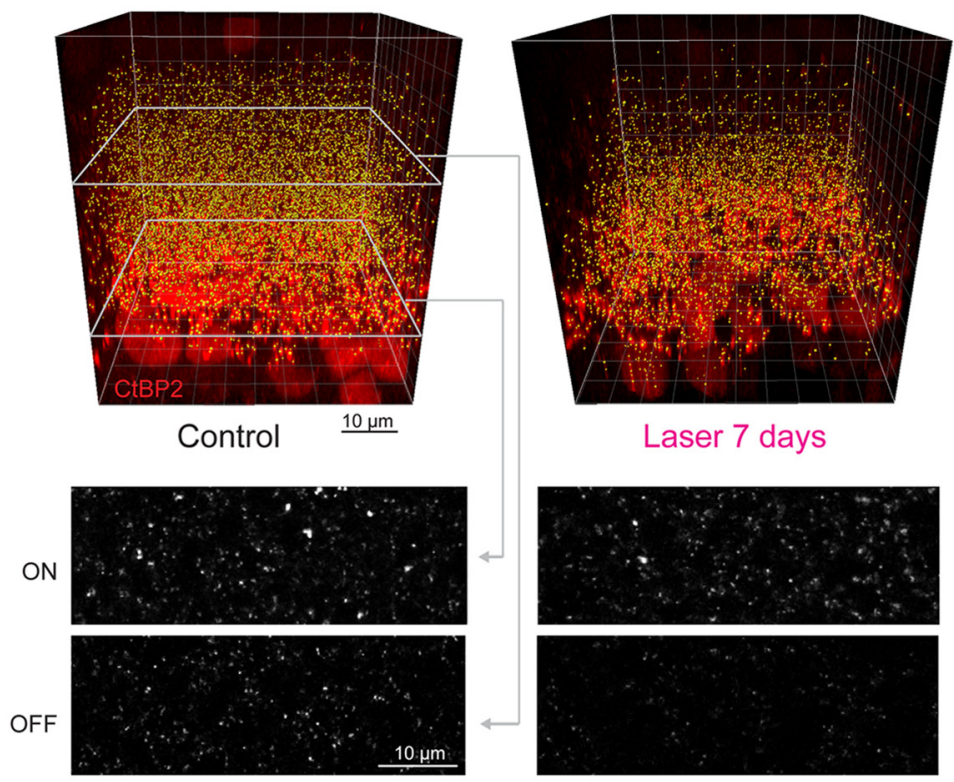

Laser 7 days
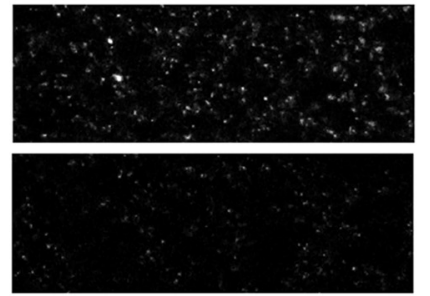

B

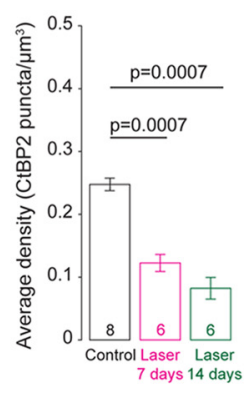

C

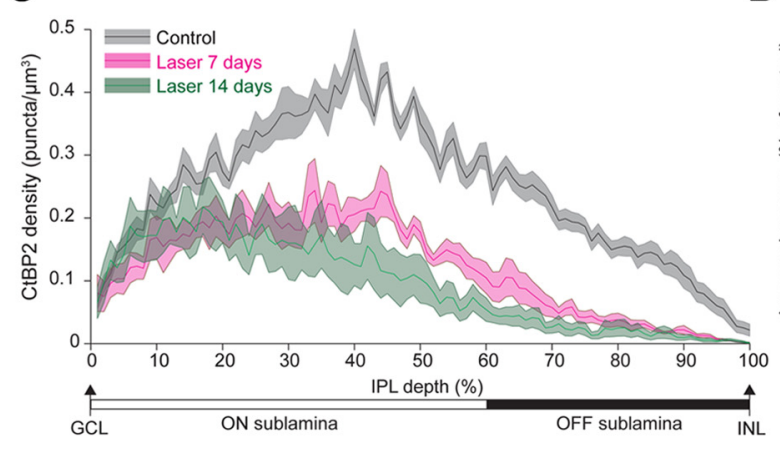

D

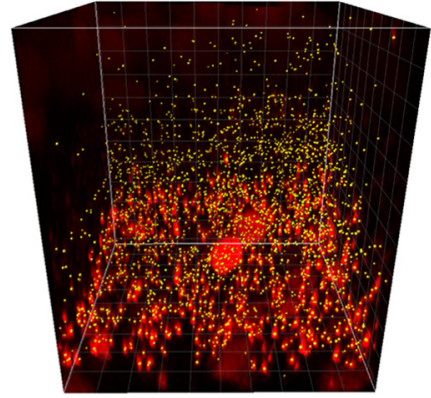

Laser 14 days
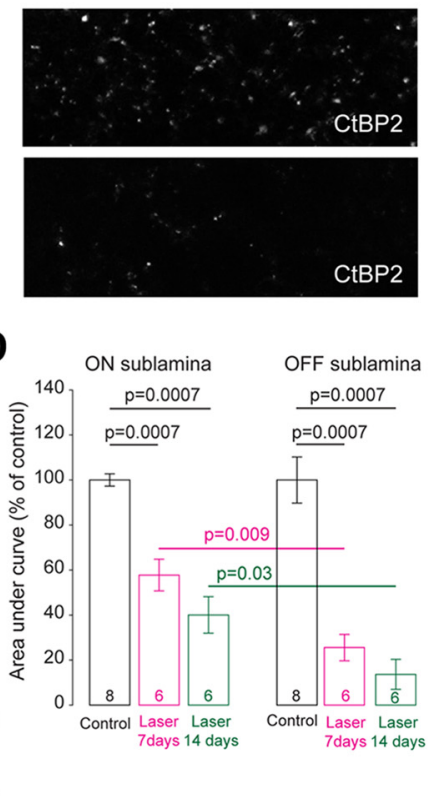

Figure 8. Presynaptic ribbon density is more rapidly and dramatically reduced in the OFF versus ON sublamina of the IPL. A, Confocal reconstruction of a representative IPL volume labeled by presynaptic ribbon marker CtBP2 (red signal), in which putative ribbon synapse locations (yellow dots) were identified using semiautomatic detection from control and laser-induced ocular hypertensive eyes ( 7 and $14 \mathrm{~d}$; see Materials and Methods). Bottom panels, Single confocal planes imaged at the levels of $0 \mathrm{~N}$ and $0 \mathrm{FF}$ sublaminae indicated in the above volumes. $\boldsymbol{B}$, Average of total ribbon synapse density in IPL volumes is lower in retinas from 7 and $14 \mathrm{~d}$ laser-induced ocular hypertensive eyes compared with control eyes. C, Ribbon synapse distribution of the same volumes in $A$ as a function of IPL depth. D, Quantification of the area under the curve reveals that not only is there a reduction in ribbon synapses in the $0 \mathrm{~N}$ and $0 \mathrm{FF}$ sublamina at 7 and $14 \mathrm{~d}$ after IOP elevation, but that there is greater loss in the OFF compared with the $\mathrm{ON}$ sublamina. Number of IPL volumes quantified are noted in the histograms; 6 - 8 animals per group. Statistics: Wilcoxon-Mann-Whitney rank sum test.

general pattern of synaptic loss. To assess sublamina-specific synapse disassembly, we immunolabeled retinas with antiCtBP2, a presynaptic marker of ribbon synapses. We then quantified CtBP2 puncta density in an IPL volume and as a function of IPL depth (see Materials and Methods). At 7 and $14 \mathrm{~d}$ after IOP elevation, average ribbon density was significantly decreased compared with control $(0.12 \pm 0.05$ and $0.08 \pm 0.03$ vs $0.24 \pm 0.09$ puncta $/ \mu \mathrm{m}^{3}$ ) (Fig. $\left.8 A, B\right)$. Furthermore, when ribbon density was quantified as a function of IPL depth, we found a greater decrease of CtBP2 puncta in the OFF versus $O N$ sublamina ( $N=6-8$ animals per group) (Fig. $8 C, D)$. This observation suggests that presynaptic disassembly

\section{$\leftarrow$}

(Figure legend continued.) spontaneous activity. C, Quantification of the average RF center size shows that only OFF-transient RGCs show a decrease RF center size 7 and $14 \mathrm{~d}$ after IOP elevation. $\boldsymbol{D}$, Average spike rates as a function of the generator signal. Cumulative distribution functions were fitted (lines) to the experimental data points. $\boldsymbol{E}$, The maximum spike rate is decreased only for OFF-transient RGCS. For the definition of these parameters, see Materials and Methods. Numbers in histograms indicate number of cells recorded; 6 mice per group. Statistics: Wilcoxon-Mann-Whitney rank sum test. might first begin in the OFF sublamina of the IPL, which is consistent with the more rapid loss of dendrites of OFFstratifying $\alpha$ RGCs to IOP elevation.

\section{OFF arbors lose complexity more rapidly compared with ON arbors within individual ON-OFF RGCs}

Previous work from El-Danaf and Huberman (2015) demonstrated that, in the microbead model, ON dendrites increased in length, whereas OFF dendrites decreased in length in ON-OFF direction-selective RGCs. To directly assess whether the relatively greater rate of presynaptic ribbon loss in the OFF versus ON sublamina we observed here correlates with differential rates of postsynaptic changes even within the same cell, we examined the dendrites of ON-OFF RGCs $7 \mathrm{~d}$ after IOP elevation (Fig. 9A). Sholl analysis reveals that OFF dendrites of ON-OFF RGCs undergo a significant and rapid reduction of complexity $(630 \pm 89$ vs $1138 \pm 141$ total intersections, $p=0.012, N=4-6$ animals per group), whereas the complexity of the $\mathrm{ON}$ arbor is unaltered compared with control (794 \pm 114 vs $840 \pm 83$ intersections, $p=$ 0.69) (Fig. 9B,C). To assess whether the observed differential reduction of dendritic complexity is accompanied by loss of syn- 
A
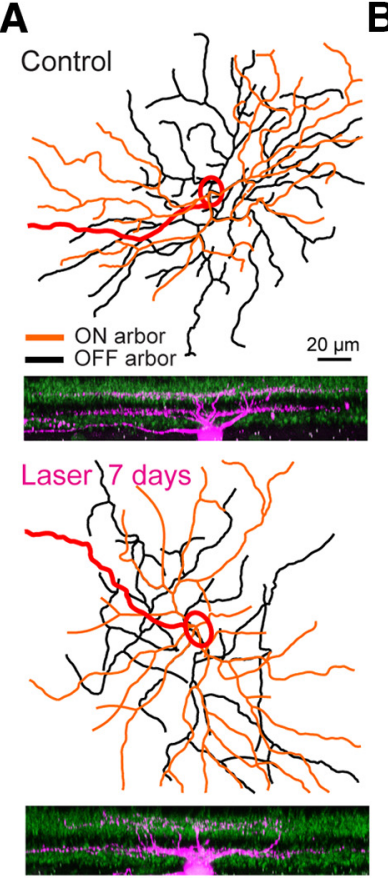

B
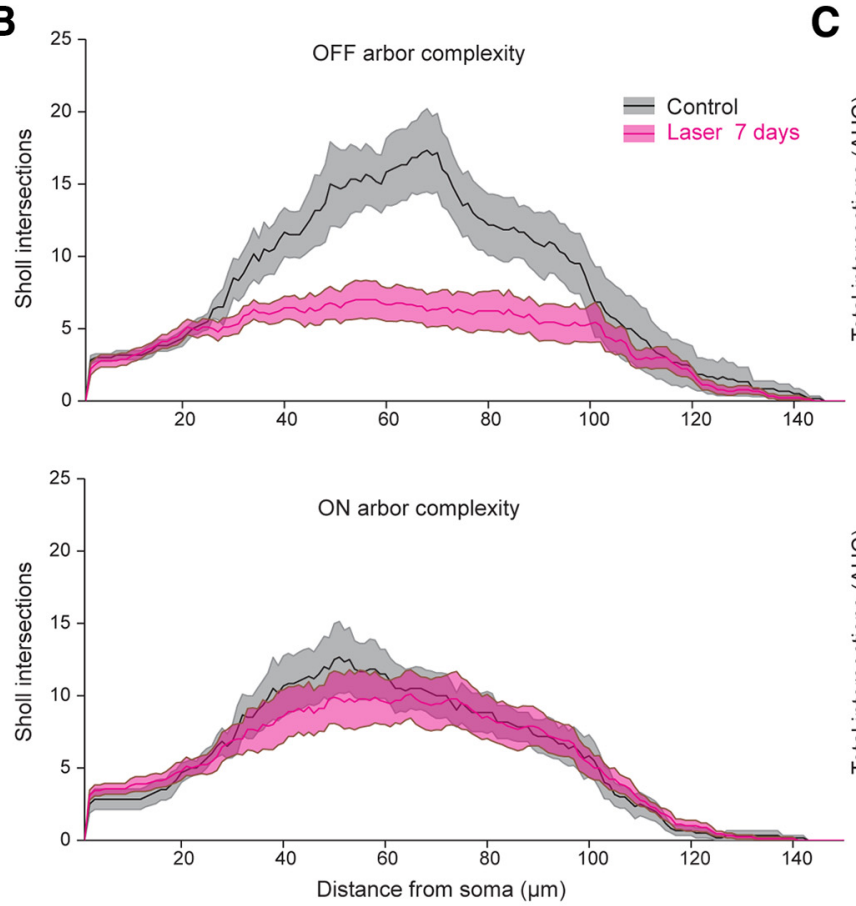

C
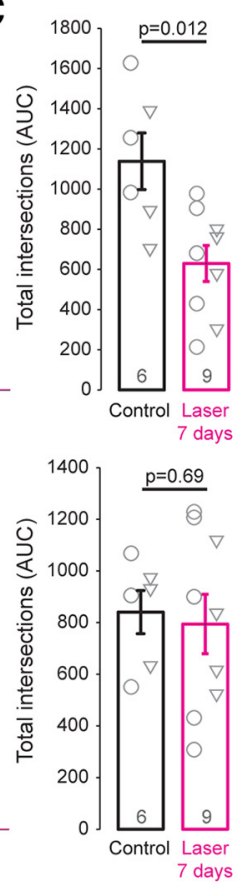

D
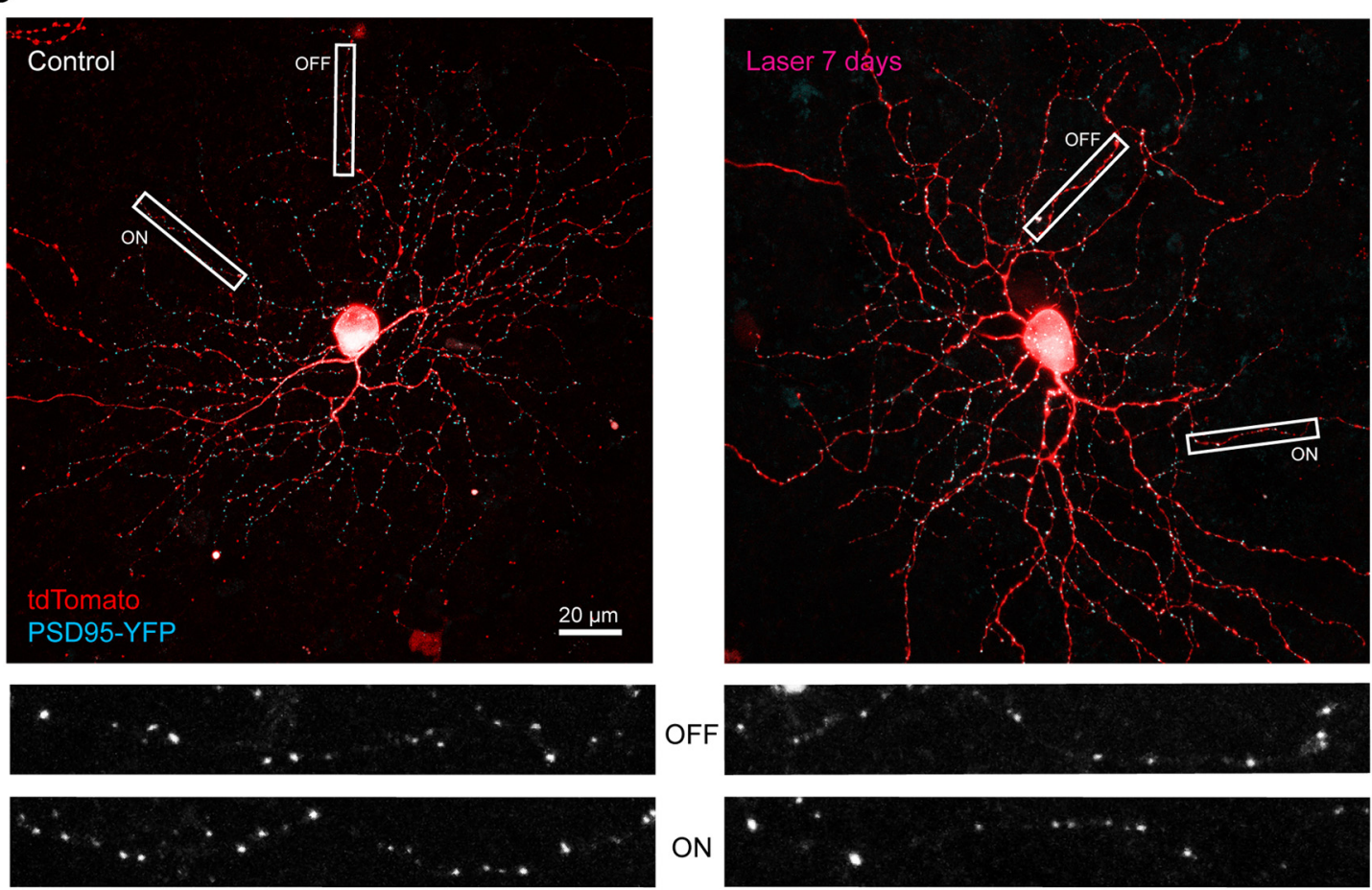

ON

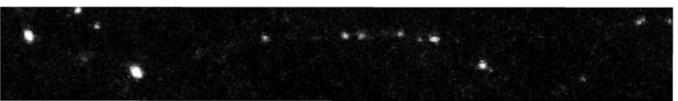

E
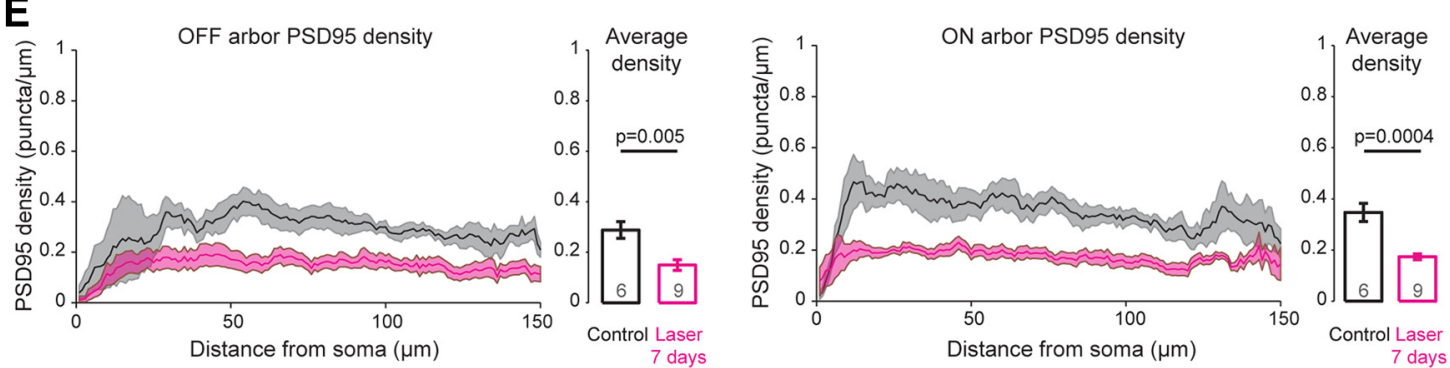

Figure 9. OFF arbors lose complexity more rapidly than ON arbors in ON-OFF RGCS. A, Dendritic arbors of ON-OFF RGCs examined in control and lasered eyes. Dendritic arbors (orange represents ON arbor; black represents OFF arbor) skeletonized from confocal image stacks of ON-OFF RG(s in control and laser-induced ocular hypertensive eyes $7 \mathrm{~d}$ after treatment. Red represents cell body and axon of the cell. Orthogonal rotations of the dendritic arbors are shown below the $x-y$ views as maximum intensity projections of the confocal image stack. Magenta (Figure legend continues.) 
apses, we analyzed PSD95 distribution within the same ON-OFF RGCs (Fig. 9D). Quantification of PSD95 density as a function of distance from the soma shows a similar reduction of excitatory synapses onto dendrites of both the ON and OFF arbors (Fig. 9E). Average PSD95 density $7 \mathrm{~d}$ after ocular hypertension is significantly lower than control for both ON and OFF dendritic arbors. Thus, in ON-OFF RGCs, PSD95 density is already reduced along ON dendrites of ON-OFF RGCs when the ON arbors still have normal dendritic complexity, indicating that loss of excitatory synapses occurs before dendritic pruning. Finally, while both ON and OFF arbors lose synapses, OFF arbors showed a more rapid loss of complexity, which is consistent with the finding that there is greater loss of presynaptic ribbons in the OFF compared with the ON sublamina of the IPL by $7 \mathrm{~d}$ after IOP elevation.

\section{Discussion}

We used a mouse model of transient ocular hypertension to explore how a subset of RGCs responds to short-term IOP elevation and ask the following questions: (1) Are there RGC types that are more susceptible to transient IOP elevation? (2) Anatomically, are the dendrites and synapses differentially affected across types? (3) Functionally, are there alterations in activity specific to functionally distinct types of RGCs? (4) Are there specific sublaminae within the IPL in which synapses are more vulnerable? While previous studies have addressed some of these questions, here we examined in detail all these aspects of early RGC degeneration in a model in which the IOP returns to baseline before assessment of structure and function. Thus, the changes we measured are a result of initial damage generated by elevated IOP but continues once IOP is normalized. This may mimic the ongoing damage after IOP is normalized after an acute angle closure crisis, intermittent angle closure, or potentially the ongoing visual deterioration of glaucoma patients undergoing treatment (Heijl et al., 2002; Ederer et al., 2004).

\section{OFF-transient $\alpha$ RGCs are selectively vulnerable across $\alpha$ RGCs to transient IOP elevation}

Here we studied $\alpha$ RGCs because these RGCs exhibit strong structure-function correlations and are identifiable morphologically. We recognize that $\alpha$ RGCs only account for an estimated $4 \%$ of all mouse RGCs (Sanes and Masland, 2015), but by examining differences among these types we gained valuable insights into a major group of RGCs, which have been studied extensively and can be followed reliably across conditions. Our finding that $\alpha$ OFF-T RGCs die at a greater rate than $\alpha$ ON-S RGCs is supported by previous studies that identified this type as especially vulnerable (Della Santina et al., 2013; El-Danaf and Huberman,

\footnotetext{
(Figure legend continued.) represents cell labeling. Green labeling represents axon staining of Type 2 (upper band) and Type 6 (lower band) bipolar cells by synaptotagmin 2, used here to delineate IPL stratification level. $\boldsymbol{B}$, Sholl analysis of OFF (top) and ON (bottom) arbors of ON-OFF RGCS. Solid line indicates average value of sampled cells. Colored band indicates SEM. Cell numbers are noted in the histograms; $4-6$ animals per group. C, Quantification of dendritic complexity of the $\mathrm{ON}$ and $\mathrm{OFF}$ arbors. Gray represents individual cell values. Circles represent nasal retina. Triangles represent temporal retina. Statistics: Wilcoxon-Mann-Whitney rank sum test. $\boldsymbol{D}$, Example of biolistically labeled ON-0FF RGCS (tdTomato) in laser-induced ocular hypertensive (7 d) and control eyes showing expression of PSD95-YFP. Bottom panels, Magnified views of PSD95 puncta on OFF and ON dendrites from the boxed regions in $\boldsymbol{D}$. $\boldsymbol{E}$, Average linear density of PSD95-YFP puncta as a function of distance from the soma. Solid line indicates average value of sampled cells. Colored band indicates SEM. Histograms, Average linear density of PSD95-YFP puncta. Cell numbers are noted in the histograms; $4-6$ animals per group. Statistics: Wilcoxon-Mann-Whitney rank sum test.
}

2015). We further demonstrate a decrease in dendritic area and complexity of $\alpha$ OFF-T RGCs and pruning of excitatory postsynaptic sites in all $\alpha$ RGC types. In accordance with the morphological changes, we found decreased spontaneous activity and RF size specific to OFF-T RGCs. Because these functional groups include non- $\alpha$ ganglion cells, these data raise the possibility that other non- $\alpha$ OFF RGCs may also exhibit deficits before ON RGCs. Indeed, the finding that the density of presynaptic ribbons was lost to a greater degree in the OFF versus ON sublamina of the IPL supports this possibility. This intriguing finding also corroborates an emerging hypothesis that RGCs with dendrites projecting into the OFF sublamina are relatively rapidly susceptible to IOP elevations (El-Danaf and Huberman, 2015). This report not only demonstrated that $\alpha$ OFF-T RGCs underwent dendritic shrinkage and increased rates of cell loss early after microbead injection, but also that in ON-OFF direction-selective RGCs, ON arbors expanded while OFF arbors shrunk. Indeed, we also found that OFF arbors of ON-OFF RGCs lost complexity whereas ON arbors did not. In addition, El-Danaf and Huberman (2015) found that M1 intrinsically photosensitive RGCs, which are functionally ON RGCs but have dendrites stratifying in the OFF sublamina, exhibited dendritic shrinkage. Overall, our findings are consistent with previous studies that used different strains and models of IOP elevation, which is important given the fact that the CD-1 strain used here may be more vulnerable to ocular hypertension (Cone et al., 2010).

However, the inability to comprehensively examine all RGC types is a limitation of any study investigating which RGC types are more susceptible, and will likely be a limitation until all mouse RGC types are definitively and easily identified (Sanes and Masland, 2015; Baden et al., 2016). Indeed, as our ability to identify and characterize RGC types improves, we better understand the context and findings of previous studies. A long history of work suggested that larger RGCs are more vulnerable (Quigley et al., 1987, 1988; Glovinsky et al., 1991; Vickers et al., 1995; Quigley, 1999; Moon et al., 2005), but different RGC types that had large somata could not be distinguished at that time. Other studies suggested that either there was no type specificity in RGC death (Jakobs et al., 2005) or that dendritic shrinkage favored ON RGCs with smaller dendritic areas (Feng et al., 2013). However, these analyses were generally performed at late stages of degeneration or may not have sampled enough types. Functionally, Pang et al. (2015) found decreased sensitivity of both ON and OFF-S $\alpha$ RGCs via the suppression of rod ON BC inputs onto AII amacrine cells. The differences from our study may be due to the fact that our MEA recordings were performed under light adapting background, thus identifying cone-driven light responses. Using the microbead occlusion model, Weitlauf et al. (2014) showed that spontaneous activity actually increased at 4 weeks, but this analysis included a mixed population of ON, OFF, and ON-OFF RGCs and excluded RGCs with very low spontaneous firing rates (Ward et al., 2014). Indeed, the differences across studies to date underscore the importance of strain, model, IOP level, stage of degeneration, and the type of measurement when investigating patterns of RGC type-specific degeneration.

\section{Sequence of RGC degeneration after transient IOP elevation}

It is important to understand the earliest structural and functional changes to an injured RGC because it provides insight into their potential reversibility and timing of treatments. Our previous work suggested a window during which RGCs are functionally impaired but maintain relatively normal dendritic morphology (Della Santina et al., 2013). We proposed a sequence of events in which RGCs lose 
synapses leading to a reduction in spontaneous activity, followed by a reduction in RF size and dendritic shrinkage. Similarly, at the output end of the RGC, Crish et al. (2010) demonstrated a window in which axonal transport was impaired but axonal and synaptic structures persisted. The present study supports the hypothesis that early changes after IOP elevation may include synapse loss onto RGCs and functional deficits. Interestingly, the sequence of events is consistent across experimental glaucoma models in which IOP is transiently or chronically elevated. This suggests that the initial insult of IOP elevation sets off a sequence that is subsequently IOP-independent. Although our data support synapse loss as an early and perhaps first anatomic change in RGC degeneration, other studies suggest that dendritic remodeling and synapse pruning occur simultaneously (Berry et al., 2015). We suspect that these discrepancies are a result of limited time points and the level of degeneration of the RGC examined. Certainly, the presence of a critical window during which synapses are lost, but major structural alterations have not yet occurred, is a promising target for therapy. Furthermore, we should explore whether synapse loss is itself the initiating event or rather the "readout" of early RGC injury initiated by axonal compression.

\section{Synaptic vulnerability of the OFF sublamina and implications for clinical treatment}

A key finding of our study is that we examined sublamina-specific changes in RGC synapses, which, to our knowledge, has not been previously examined in experimental glaucoma. Prior studies suggest that total synapses are lost after IOP elevation, but there may be compensatory attempts to regenerate immature synapses (Park et al., 2014). Here we found that PSD95-labeled postsynaptic sites were lost across all $\alpha$ RGCs, but presynaptic ribbon synapses were lost to a greater degree in the OFF versus ON sublamina of the IPL. It is possible that, if we were to examine earlier after transient IOP elevation, we would find differential PSD95 density loss across types. But what accounts for the greater loss of presynaptic ribbons in the OFF versus ON sublamina? One possibility is that more OFF bipolar cells (BCs) are losing ribbons compared with ON BCs. Additionally, it is possible that presynaptic ribbons are lost before postsynaptic sites. Even the finding of presynaptic ribbon loss itself is interesting because it may reflect BC death (perhaps in a type-specific manner); and while prior studies have not shown this (Vickers et al., 1995; Jakobs et al., 2005; Moon et al., 2005), others have noted a reduction of ON BC processes (Cuenca et al., 2010; Fernández-Sánchez et al., 2014). Future work is needed to unravel the relative timing of presynaptic and postsynaptic alterations to understand the sequence of synapse disassembly.

Another important question is why RGCs with processes in the OFF sublamina are particularly susceptible to IOP elevation. El-Danaf and Huberman (2015) suggested that the proximity of this sublamina to the vasculature makes it especially susceptible to vascular damage. Alternative hypotheses include differential gradients of neurotrophic factors or chemical mediators that may result in relative protection in the $\mathrm{ON}$ versus OFF sublamina or cell type-intrinsic factors that render one type more readily perturbed than another. Previous work suggests that OFF pathways in cat and ferret are more metabolically active than ON pathways, which could contribute to differential susceptibility (Kageyama and Wong-Riley, 1984). Regardless of the underlying reason for the ON and OFF sublamina differences, our study underscores the importance of investigating the sequence and spatiotemporal relationships of early degeneration in specific RGC types in all model systems, including nonhuman primates, to eventually de- sign more sensitive functional tests and neuroprotective or neuroenhancing treatments in humans.

\section{References}

Andreatta W, Nessim M, Nightingale P, Shah P (2014) ReGAE 10: longterm visual acuity outcomes after acute primary angle closure. J Glaucoma 23:206-210. CrossRef Medline

Andreatta W, Elaroud I, Nightingale P, Nessim M (2015) Long-term outcomes after acute primary angle closure in a White Caucasian population. BMC Ophthalmol 15:108. CrossRef Medline

Aung T, Friedman DS, Chew PT, Ang LP, Gazzard G, Lai YF, Yip L, Lai H, Quigley H, Seah SK (2004) Long-term outcomes in Asians after acute primary angle closure. Ophthalmology 111:1464-1469. CrossRef Medline

Baden T, Berens P, Franke K, Román Rosón M, Bethge M, Euler T (2016) The functional diversity of retinal ganglion cells in the mouse. Nature 529:345-350. CrossRef Medline

Berry RH, Qu J, John SW, Howell GR, Jakobs TC (2015) Synapse loss and dendrite remodeling in a mouse model of glaucoma. PLoS One 10: e0144341. CrossRef Medline

Bleckert A, Schwartz GW, Turner MH, Rieke F, Wong RO (2014) Visual space is represented by nonmatching topographies of distinct mouse retinal ganglion cell types. Curr Biol 24:310-315. CrossRef Medline

Cleland BG, Levick WR, Wässle H (1975) Physiological identification of a morphological class of cat retinal ganglion cells. J Physiol 248:151-171. CrossRef Medline

Cone FE, Gelman SE, Son JL, Pease ME, Quigley HA (2010) Differential susceptibility to experimental glaucoma among 3 mouse strains using bead and viscoelastic injection. Exp Eye Res 91:415-424. CrossRef Medline

Coombs J, van der List D, Wang GY, Chalupa LM (2006) Morphological properties of mouse retinal ganglion cells. Neuroscience 140:123-136. CrossRef Medline

Crish SD, Sappington RM, Inman DM, Horner PJ, Calkins DJ (2010) Distal axonopathy with structural persistence in glaucomatous neurodegeneration. Proc Natl Acad Sci U S A 107:5196-5201. CrossRef Medline

Cuenca N, Pinilla I, Fernández-Sánchez L, Salinas-Navarro M, AlarcónMartínez L, Avilés-Trigueros M, de la Villa P, Miralles de Imperial J, Villegas-Pérez MP, Vidal-Sanz M (2010) Changes in the inner and outer retinal layers after acute increase of the intraocular pressure in adult albino Swiss mice. Exp Eye Res 91:273-285. CrossRef Medline

Della Santina L, Inman DM, Lupien CB, Horner PJ, Wong RO (2013) Differential progression of structural and functional alterations in distinct retinal ganglion cell types in a mouse model of glaucoma. J Neurosci 33:17444-17457. CrossRef Medline

Demas J, Eglen SJ, Wong RO (2003) Developmental loss of synchronous spontaneous activity in the mouse retina is independent of visual experience. J Neurosci 23:2851-2860. Medline

Desai KH, Sato R, Schauble E, Barsh GS, Kobilka BK, Bernstein D (1997) Cardiovascular indexes in the mouse at rest and with exercise: new tools to study models of cardiac disease. Am J Physiol 272:H1053-H1061. Medline

Ederer F, Gaasterland DA, Dally LG, Kim J, VanVeldhuisen PC, Blackwell B, Prum B, Shafranov G, Allen RC, Beck A (2004) The Advanced Glaucoma Intervention Study (AGIS): 13. Comparison of treatment outcomes within race: 10-year results. Ophthalmology 111:651-664. CrossRef Medline

El-Danaf RN, Huberman AD (2015) Characteristic patterns of dendritic remodeling in early-stage glaucoma: evidence from genetically identified retinal ganglion cell types. J Neurosci 35:2329-2343. CrossRef Medline

Famiglietti EV Jr, Kolb H (1976) Structural basis for ON-and OFF-center responses in retinal ganglion cells. Science 194:193-195. CrossRef Medline

Famiglietti EV Jr, Kaneko A, Tachibana M (1977) Neuronal architecture of on and off pathways to ganglion cells in carp retina. Science 198:12671269. CrossRef Medline

Feng L, Zhao Y, Yoshida M, Chen H, Yang JF, Kim TS, Cang J, Troy JB, Liu X (2013) Sustained ocular hypertension induces dendritic degeneration of mouse retinal ganglion cells that depends on cell type and location. Invest Ophthalmol Vis Sci 54:1106-1117. CrossRef Medline

Fernández-Sánchez L, de Sevilla Müller LP, Brecha NC, Cuenca N (2014) Loss of outer retinal neurons and circuitry alterations in the DBA/2J mouse. Invest Ophthalmol Vis Sci 55:6059-6072. CrossRef Medline

Fu CT, Sretavan D (2010) Laser-induced ocular hypertension in albino CD-1 mice. Invest Ophthalmol Vis Sci 51:980-990. CrossRef Medline 
Glovinsky Y, Quigley HA, Dunkelberger GR (1991) Retinal ganglion cell loss is size dependent in experimental glaucoma. Invest Ophthalmol Vis Sci 32:484-491. Medline

Heijl A, Leske MC, Bengtsson B, Hyman L, Bengtsson B, Hussein M (2002) Reduction of intraocular pressure and glaucoma progression: results from the Early Manifest Glaucoma Trial. Arch Ophthalmol 120:12681279. CrossRef Medline

Huberman AD, Manu M, Koch SM, Susman MW, Lutz AB, Ullian EM, Baccus SA, Barres BA (2008) Architecture and activity-mediated refinement of axonal projections from a mosaic of genetically identified retinal ganglion cells. Neuron 59:425-438. CrossRef Medline

Jakobs TC, Libby RT, Ben Y, John SW, Masland RH (2005) Retinal ganglion cell degeneration is topological but not cell type specific in DBA/2J mice. J Cell Biol 171:313-325. CrossRef Medline

Kageyama GH, Wong-Riley MT (1984) The histochemical localization of cytochrome oxidase in the retina and lateral geniculate nucleus of the ferret, cat, and monkey, with particular reference to retinal mosaics and ON/OFF-center visual channels. J Neurosci 4:2445-2459. Medline

Kerschensteiner D, Liu H, Cheng CW, Demas J, Cheng SH, Hui CC, Chow RL, Wong RO (2008) Genetic control of circuit function: Vsx1 and Irx5 transcription factors regulate contrast adaptation in the mouse retina. J Neurosci 28:2342-2352. CrossRef Medline

Li RS, Chen BY, Tay DK, Chan HH, Pu ML, So KF (2006) Melanopsinexpressing retinal ganglion cells are more injury-resistant in a chronic ocular hypertension model. Invest Ophthalmol Vis Sci 47:2951-2958. CrossRef Medline

Moon JI, Kim IB, Gwon JS, Park MH, Kang TH, Lim EJ, Choi KR, Chun MH (2005) Changes in retinal neuronal populations in the DBA/2J mouse. Cell Tissue Res 320:51-59. CrossRef Medline

Morgan JE, Uchida H, Caprioli J (2000) Retinal ganglion cell death in experimental glaucoma. Br J Ophthalmol 84:303-310. CrossRef Medline

Morgan JL, Schubert T, Wong RO (2008) Developmental patterning of glutamatergic synapses onto retinal ganglion cells. Neural Dev 3:8. CrossRef Medline

Pang JJ, Gao F, Wu SM (2003) Light-evoked excitatory and inhibitory synaptic inputs to ON and OFF alpha ganglion cells in the mouse retina. J Neurosci 23:6063-6073. Medline

Pang JJ, Frankfort BJ, Gross RL, Wu SM (2015) Elevated intraocular pressure decreases response sensitivity of inner retinal neurons in experimental glaucoma mice. Proc Natl Acad Sci U S A 112:2593-2598. CrossRef Medline

Park HY, Kim JH, Park CK (2014) Alterations of the synapse of the inner retinal layers after chronic intraocular pressure elevation in glaucoma animal model. Mol Brain 7:53. CrossRef Medline

Pavlidis M, Stupp T, Naskar R, Cengiz C, Thanos S (2003) Retinal ganglion cells resistant to advanced glaucoma: a postmortem study of human retinas with the carbocyanine dye DiI. Invest Ophthalmol Vis Sci 44: 5196-5205. CrossRef Medline

Quigley HA (1999) Neuronal death in glaucoma. Prog Retin Eye Res 18: 39-57. CrossRef Medline
Quigley HA, Broman AT (2006) The number of people with glaucoma worldwide in 2010 and 2020. Br J Ophthalmol 90:262-267. CrossRef Medline

Quigley HA, Sanchez RM, Dunkelberger GR, L'Hernault NL, Baginski TA (1987) Chronic glaucoma selectively damages large optic nerve fibers. Invest Ophthalmol Vis Sci 28:913-920. Medline

Quigley HA, Dunkelberger GR, Green WR (1988) Chronic human glaucoma causing selectively greater loss of large optic nerve fibers. Ophthalmology 95:357-363. CrossRef Medline

Salinas-Navarro M, Alarcón-Martínez L, Valiente-Soriano FJ, OrtínMartínez A, Jiménez-López M, Avilés-Trigueros M, Villegas-Pérez MP, de la Villa P, Vidal-Sanz M (2009) Functional and morphological effects of laser-induced ocular hypertension in retinas of adult albino Swiss mice. Mol Vis 15:2578-2598. Medline

Sanes JR, Masland RH (2015) The types of retinal ganglion cells: current status and implications for neuronal classification. Annu Rev Neurosci 38:150421150146009. CrossRef Medline

Schubert T, Degen J, Willecke K, Hormuzdi SG, Monyer H, Weiler R (2005) Connexin36 mediates gap junctional coupling of alpha-ganglion cells in mouse retina. J Comp Neurol 485:191-201. CrossRef Medline

Seeley WW (2008) Selective functional, regional, and neuronal vulnerability in frontotemporal dementia. Curr Opin Neurol 21:701-707. CrossRef Medline

Shou T, Liu J, Wang W, Zhou Y, Zhao K (2003) Differential dendritic shrinkage of alpha and beta retinal ganglion cells in cats with chronic glaucoma. Invest Ophthalmol Vis Sci 44:3005-3010. CrossRef Medline

Tian N, Copenhagen DR (2001) Visual deprivation alters development of synaptic function in inner retina after eye opening. Neuron 32:439-449. CrossRef Medline

van Wyk M, Wässle H, Taylor WR (2009) Receptive field properties of ONand OFF-ganglion cells in the mouse retina. Vis Neurosci 26:297-308. CrossRef Medline

Vickers JC, Schumer RA, Podos SM, Wang RF, Riederer BM, Morrison JH (1995) Differential vulnerability of neurochemically identified subpopulations of retinal neurons in a monkey model of glaucoma. Brain Res 680:23-35. CrossRef Medline

Völgyi B, Abrams J, Paul DL, Bloomfield SA (2005) Morphology and tracer coupling pattern of alpha ganglion cells in the mouse retina. J Comp Neurol 492:66-77. CrossRef Medline

Ward NJ, Ho KW, Lambert WS, Weitlauf C, Calkins DJ (2014) Absence of transient receptor potential vanilloid-1 accelerates stress-induced axonopathy in the optic projection. J Neurosci 34:3161-3170. CrossRef Medline

Weber AJ, Kaufman PL, Hubbard WC (1998) Morphology of single ganglion cells in the glaucomatous primate retina. Invest Ophthalmol Vis Sci 39:2304-2320. Medline

Weitlauf C, Ward NJ, Lambert WS, Sidorova TN, Ho KW, Sappington RM, Calkins DJ (2014) Short-term increases in transient receptor potential vanilloid-1 mediate stress-induced enhancement of neuronal excitation. J Neurosci 34:15369-15381. CrossRef Medline 